\title{
NOTAS
}

\section{PRIMER REGISTRO DEL GÉNERO LYTOCARPIA KIRCHENPAUER, 1872 (CNIDARIA: HYDROZOA: LEPTOTHECATA), PARA CUBA}

\author{
Carlos Varela
}

Acuario Nacional de Cuba (ANC), Calle 1ra \#6002 e/e 60 y 62, C. P. 11300, Playa, La Habana, Cuba. carlosv@acuarionacional.cu

\section{RESUMEN}

Se registran por vez primera vez para el archipiélago cubano el género Lytocarpia y la especie L. distans. Este es el más somero de los hallazgos de esta especie de hidrozoo.

Palabras clave: hidrozoo, género Lytocarpia, L. distans, primer registro, archipiélago cubano.

\section{ABSTRACT}

The genus Lytocarpia and the species $L$. distans are recorded for the first time for Cuban archipielago. This is the most shallow find of this hydroid species.

Key words: hydroid, genus Lytocarpia, L. distans, first record, Cuban archipelago.

\section{INTRODUCCIÓN}

Los representantes de la familia Aglaopheniidae Marktanner-Turneretscher, 1890, han sido hallados desde las latitudes altas hasta los trópicos, y desde hábitats intermareales hasta las mayores profundidades oceánicas (Calder, 1997). Para el archipiélago cubano se han registrado hasta el presente 11 especies (Castellanos-Iglesias et al, 2009), siendo Cuba la isla del Gran Caribe con más especies registradas de esta familia. En el presente trabajo, se registran por primera vez para Cuba un género y una especie pertenecientes a esta familia.

\section{RESULTADOS \\ Lytocarpia distans (Allman, 1877)}

Figura 1

Material estudiado. Dos colonias estériles de 22 y $24 \mathrm{~cm}$ de alto, respectivamente. Colectadas en Cayo Bretón, Archipiélago de los Jardines de la Reina, provincia de Sancti Spiritus, el XII del 2008 por P. Chevalier, a 30 metros de profundidad. El material ha sido depositado en la Colección Natural Marina del Acuario Nacional de Cuba, ANC 03. 3. 120.

Diagnosis. Hidrocladios alternos, en el mismo plano, con internodos separados por nodos transversos, cada uno con una hidroteca y tres nematotecas, una medio inferior y dos laterales; septo interno pobremente desarrollado. Hidroteca profunda, alargada, más estrecha basalmente, pared adcaulina completamente adnata, borde de la hidroteca con cúspides bajas, pero con una cúspide frontal prominente. Nematoteca media inferior corta, ocupando el tercio basal de la hidroteca, nematotecas laterales pequeñas con su borde al mismo nivel del borde de la hidroteca. 


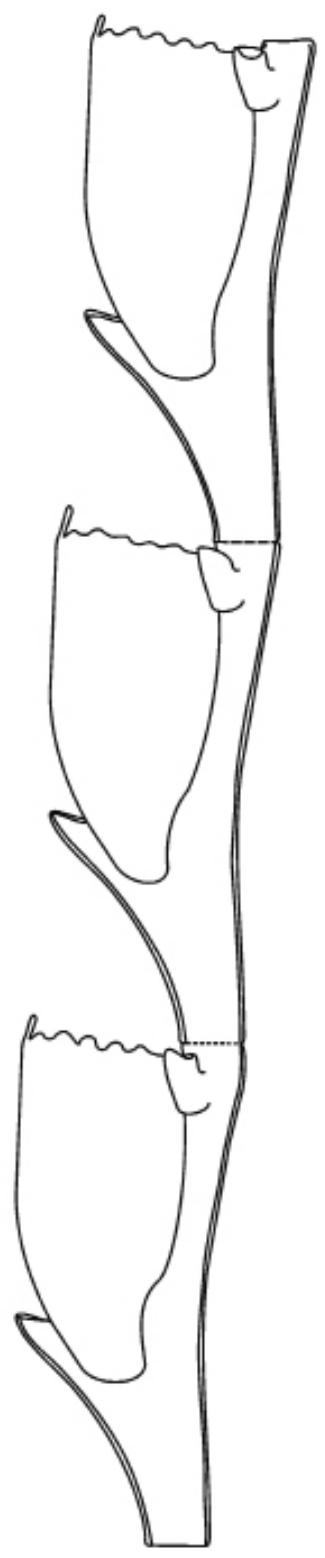

$E$
$E$
0
0

Figura 1. Lytocarpia distans. Vista lateral de tres internodos del hidrocladio con hidrotecas y nematotecas.

Observaciones. El material estudiado coincide con los caracteres dados para la especie por autores como Ramil y Vervoort (1992), Ansin-Agis et al (2001) y Bouillon et al (2004). Esta es la menor profundidad registrada para esta especie, pues previamente se había colectado desde 90 hasta 986 metros de profundidad. 


\section{AGRADECIMIENTOS}

Al amigo y colega Pedro Chevalier (Acuario Nacional de Cuba) por la colecta de las colonias.

\section{LITERATURA CITADA}

Ansin Agis, J., F. Ramil y W. Vervoort. 2001. Atlantic Leptolida (Hydrozoa, Cnidaria) of the families Aglaopheniidae, Halopteriidae, Kirchenpaueriidae and Plumulariidae collected during the CANCAP and Mauritania-II expeditions of the National Museum of Natural History, Leiden, The Netherlands. Zoologisches Verhandelingen, 333: 1-268.

Bouillon, J., M. D. Medel, F. Pagés, J. M. Gili, F. Boero y C. Gravili. 2004. Fauna of the Mediterranean Hydrozoa. Scientia Marina 68 (Supl. 2): 1- 449.

Calder, D. R. 1997. Shallow-water hydroids of Bermuda: (Superfamily Plumularioidea). Life Sciences Contributions, Royal Ontario Museum, 161: 1-85.

Castellanos-Iglesias, S., C. Varela, M. V. Orozco y M. Ortiz. 2009. Hidrozoos tecados (Cnidaria, Hydrozoa, Leptothecatae) con fase pólipo conocida de Cuba. Serie Oceanológica, 6: 1-8.

Ramil, F. y W. Vervoort. 1992. Report on the hydroida collected by the "BALGIM" expedition in and around the Strait of Gibraltar. Zoologisches Verhandelingen 277: 1- 262. 